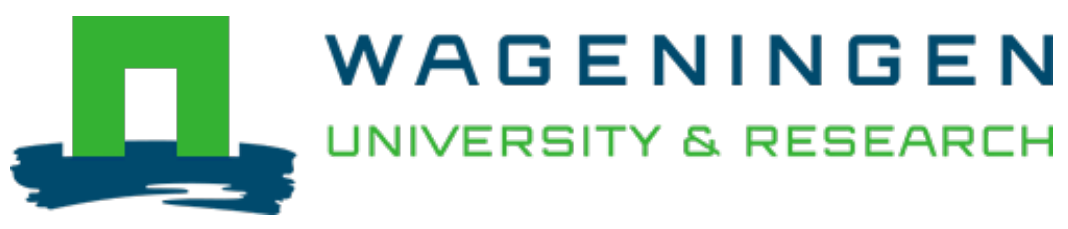

\title{
Pro-environmental behaviour in the workplace and the role of managers and organisation
}

\author{
Journal of Cleaner Production \\ Wesselink, Renate; Blok, Vincent; Ringersma, Jarno \\ https://doi.org/10.1016/j.jclepro.2017.08.214
}

This article is made publicly available in the institutional repository of Wageningen University and Research, under the terms of article $25 \mathrm{fa}$ of the Dutch Copyright Act, also known as the Amendment Taverne. This has been done with explicit consent by the author.

Article 25 fa states that the author of a short scientific work funded either wholly or partially by Dutch public funds is entitled to make that work publicly available for no consideration following a reasonable period of time after the work was first published, provided that clear reference is made to the source of the first publication of the work.

This publication is distributed under The Association of Universities in the Netherlands (VSNU) 'Article $25 \mathrm{fa}$ implementation' project. In this project research outputs of researchers employed by Dutch Universities that comply with the legal requirements of Article $25 \mathrm{fa}$ of the Dutch Copyright Act are distributed online and free of cost or other barriers in institutional repositories. Research outputs are distributed six months after their first online publication in the original published version and with proper attribution to the source of the original publication.

You are permitted to download and use the publication for personal purposes. All rights remain with the author(s) and / or copyright owner(s) of this work. Any use of the publication or parts of it other than authorised under article $25 \mathrm{fa}$ of the Dutch Copyright act is prohibited. Wageningen University \& Research and the author(s) of this publication shall not be held responsible or liable for any damages resulting from your (re)use of this publication.

For questions regarding the public availability of this article please contact openscience.library@wur.nl 


\title{
Pro-environmental behaviour in the workplace and the role of managers and organisation
}

\author{
Renate Wesselink ${ }^{\mathrm{a},{ }^{*}}$, Vincent Blok ${ }^{\mathrm{b}}$, Jarno Ringersma ${ }^{\mathrm{b}}$ \\ ${ }^{a}$ Education and Competence Studies, Department of Social Sciences, Wageningen University, Hollandseweg 1, 6706 KN Wageningen, The Netherlands \\ ${ }^{\mathrm{b}}$ Management Studies, Department of Social Sciences, Wageningen University, Hollandseweg 1, 6706 KN, Wageningen, The Netherlands
}

\section{A R T I C L E I N F O}

Article history:

Received 24 November 2016

Received in revised form

22 August 2017

Accepted 29 August 2017

Available online $\mathrm{xxx}$

Handling Editor: Yutao Wang

Keywords:

Pro-environmental behaviour

Theory of planned behaviour

Private sector

Leadership behaviour

Perceived organisational support-

environment

\begin{abstract}
A B S T R A C T
Corporate social responsibility is gaining significance in the business world. However, scholars haven't sufficiently examined the factors that influence the small, everyday sustainability behaviors that individual employees might choose to perform. This study had the aim to unravel factors that affect proenvironmental behaviour (PEB) of individual employees. In addition to the known factors of the theory of planned behaviour (attitude towards PEB, subjective norms, perceived behavioural control, and intention to act), factors as leadership support, perceived organisational support for the environment (POS-E) (taken together as institutional support), and leadership (exemplary) behaviour were taken into account. Although the relationship between intention to act and PEB was not significant in this study, based on the findings it can be concluded that leadership behaviour (as exemplary behaviour) and POS-E or in other words the perceived organisational support to act proenvironmentally friendly, are affecting both intention to act and PEB. It is remarkable that leadership support does not affect the intention to act and actual PEB.
\end{abstract}

(c) 2017 Elsevier Ltd. All rights reserved.

\section{Introduction}

Organisations increasingly acknowledge the importance of corporate sustainability and that makes that corporate social responsibility (CSR) as a strategy to reach corporate sustainability (see Marrewijk, 2003) is gaining significance in the business world. To implement CSR in existing business, CSR needs to be embedded throughout the whole organisation (Lamm et al., 2013) and integrated into a comprehensive strategy (Galpin and Whittington, 2012). Several scholars point at the shortage of research related to organisations and CSR especially on the level of the individual employee and their behaviour (Aguinis and Glavas, 2012; Robertson and Barling, 2013); factors that influence the small, everyday sustainability behaviours are not investigated enough. Given that climate change is largely driven by human activity, and the success of environmental programmes often depends on employees' behaviour (Daily et al., 2008), fostering employees' pro-

\footnotetext{
* Corresponding author.

E-mail addresses: renate.wesselink@wur.nl (R. Wesselink),vincent.blok@wur.n (V. Blok).
}

environmental behaviour (PEB) could be one of the factors that may help to deal with these grand societal challenges. Lamm et al. (2013) underpins this perspective by claiming that the overall organisations' sustainability success depends to a large extent on individual efforts. For instance, although new technologies and facilities are vital to the success of implementing CSR (e.g. energysavings), the readiness of individual employees to actively embrace pro-environmental behaviours that sustain the natural environment is crucial as well (Graves et al., 2013). This shows that strategic initiatives cannot be implemented without the active support and participation of individual employees; the employee perspective is absolutely essential. The impact of one individual's decision might seem small, in the aggregate, the impact will be significant (Stern, 2000).

However, employee participation is complicated; for the majority of employees, PEB is not a required task, but rather voluntary behaviour (Ramus and Killner, 2007). Whereas these voluntarily behaviours are studied in households, it has rarely been studied in workplace settings (Blok et al., 2015; Ones and Dilchert, 2012). The few empirical studies that are performed, report that employee behaviour towards corporate greening or CSR is associated with pollution prevention, more efficient environmental management 
systems, improvements in environmental performance, and green innovations (e.g. Andersson and Bateman, 2000; Ramus and Killner, 2007). However, the specific nature of employee involvement and their contribution in corporate greening or CSR remains unclear. It has been proven that although value frames (e.g. unlimited economic growth is ultimately unsustainable) are fairly well established, it still remains difficult to locate a causal relationship between pro-environmental attitudes and deliberate, proenvironmental behaviour (e.g. Blok et al., 2015). Generalized attitudes as such are not very good predictors of environmentally responsible action (Blok et al., 2015; Poortinga et al., 2004; Schultz et al., 1995). The models that do show a strong predictive power between attitudes and responsible action, tend to employ a set of very narrowly defined attitudes and behaviours (Oskamp et al., 1991; Ungar, 1994).

A fairly well recognized driver for environmentally responsible behaviour is the combination of social support, deliberation, and feedback in particular situations (e.g. households, workplaces). Nevertheless, Nye and Hargreaves (2010) show that this mechanism works very different in different social contexts. This underpins the premise that social contexts should be understood and accounted for as part of the dynamics of behavioural interventions, rather than as an external force affecting individual employee behaviour or some kind of remainder for the elements of behaviour that cannot be explained by pro-environmental attitudes and social preferences. Therefore, mechanisms should not be taken in isolation of their contexts; without the context it is rather difficult to create an accurate picture of what is actually going on. Blok et al. (2015) is one of the first teams that studied factors affecting PEB in the workplace in which the context was included. Their study was situated in a public sector (e.g. green university) and based on their findings they conclude that leaders (e.g. line managers) can influence employees' PEB by supporting PEB and showing PEB themselves. Current study follows the line of reasoning started by Blok et al. (2015) and attempts to understand which factors do influence the discretionary pro-environmental behaviour of employees in a private company context. Knowing the different and sometimes even competing logics between private (e.g. business logic) and public (e.g. social logic) sectors, this study might reveal other factors affecting PEB in comparison to studies that took place in public sectors (e.g. Blok et al., 2015). The particular context chosen in this research are housing associations. Housing associations are under governmental regulation and all share the same social goal: provide (rental) housing for lower income households. Seemingly similar from this point of view, the associations however are relatively free in employing commercial business, making every association very different.

The point of departure in determining which factors affect proenvironmental behaviour is Ajzen's theory of planned behaviour (TPB) (Ajzen, 1991), because it has proven its value in former research studies on PEB (Blok et al., 2015; Nye and Hargreaves, 2010). This theory suggests that behaviours result from the interaction of attitudes, subjective normative perceptions and perceived behavioural control (PBC), in which $\mathrm{PBC}$ represents to what extent individuals feel they are in control to perform a certain kind of behaviour in a particular context. Many studies use TPB to find out to what extent 'contextualised inputs' (i.e. PBC) predict $\mathrm{PEB}$, because as suggested, context needs to be taken into account. In general it can be concluded, based on that body of knowledge, that the attitude-behaviour relation is the strongest in situations when contextual factors are neutral (Nye and Hargreaves, 2010). And when contextual factors are either strongly positive or negative, the predictive value of attitudes seems to be minimal for explaining behaviour. Additionally, based on a review of McEachan et al. (2011) it can be stated that when
$\mathrm{PBC}$ is high, an individuals' intention is the main predictor of behaviour and PBC does not predict behaviour at all. In the current discourse on PEB in the workplace, it is quite common to include additional factors (and not solely the TPB factors) which could explain PEB. Behaviour in the workplace is not just influenced by the employees' intentions or attitudes, one might expect that the organisation, colleagues and direct supervisors also affect PEB. Therefore in this article, these factors are, besides the common TPB factors, taken into account. The next section contains the descriptions of these theoretical constructs, both of TPB and additional ones, cumulating in the specific research questions at stake. The theoretical framework will be followed by the method, results and discussion section, to finally end up with a conclusion section.

\section{Theoretical framework}

To meet the goal of this paper different strands of research can be identified as relevant. Results about PEB and organisational citizenship behaviour related to the environment (OCB-E) (Boiral, 2009) are seen as two sides of the same coin. Where PEB has its roots in research of environmental behaviour in households (Kollmuss and Agyeman, 2002), OCB-E finds its origin in socialpsychological organisational research (Boiral, 2009). PEB is defined by Kollmuss and Agyeman (2002) as individuals' behaviours that consciously seek to lessen the negative impact of their actions on the natural and built environment. Examples of this kind of behaviours in the workplace are double-sided printing, shutting down lights when leaving a room. OCB-E is defined as a voluntary behaviour that helps to make the organisation and/or society more sustainable in which voluntary means that it is not specified in an official job description (Paillé and Boiral, 2013). Employees show this behaviour because they think it is important for their company or for society at large.

An adjacent field of study is the field of employee green behaviour (EGB). Norton et al. (2014) distinguish between taskrelated and proactive EGB (reported by employees themselves) based on Bissing-Olson et al. (2013). Task-related EGB is proenvironmental behaviour performed within the context of assigned work tasks, including behaviours such as conserving water, energy, and other resources (e.g. printing double sided) and comparable to aforementioned PEB and OCB-E. Proactive EGB is behaviour that is initiated at a personal level and exceeds expectations with regard to sustainability. Proactive EGB is of a different level and oftentimes concerns the 'champions'; leaders in change or so-called CSR managers who initiate green behaviours that go beyond their assigned tasks. Norton et al. (2014) proved that these two constructs are conceptually distinct constructs. The research at stake does not focus on these so-called champions. This research focusses on task-related EGB, that goes beyond the job descriptions and is voluntary in nature and therefore the aim is to identify factors that affect PEB of the, what is called, regular employee. While in this paper the concept of PEB is used, the empirical findings on antecedents and theoretical underpinnings of OCB-E and task-related EGB are also incorporated, mainly in the section in which factors that affect PEB are identified.

\subsection{Perceived organisational support - environment (POS-E) and PEB}

Several studies are done to explore the factors that affect PEB, OCB-E and task-related EGB. Studies about employees and employee behaviour oftentimes include the constructs commitment and job satisfaction. Both constructs are seen as fairly good 
predictors of job performance whereas job performance is in general difficult to measure. However, Paillé and Boiral (2013) conclude, based on their research that there is no relation between OCB-E and job satisfaction. Commitment to the organisation is positively related to OCB-E, though. Furthermore, recent research shows that perceived organisational support for the environment (POS-E) and OCB-E are positively related (Lamm et al., 2015; Temminck et al., 2015). POS-E is "the specific belief held by employees concerning how much the organisation values their contributions toward sustainability" (Lamm et al., 2015, p.209). In former research Lamm et al. (2013) identified a positive relation between affective commitment, beliefs about the importance of sustainability and OCB-E. Although (affective) commitment does play a role in several studies, it is not taken into account in this study, because in the study done by Blok et al. (2015) mainly the external factors showed a significant contribution to PEB and therefore in this study the focus is on those external factors (e.g. the role of the managers and the organisation) and their effect on PEB. Therefore, POS-E, is taken into account. The next paragraph will explain the relevance of leadership in the framework of PEB.

\subsection{Leadership and PEB}

One way individuals learn is by observing behaviours performed by others and subsequently, initiate and show similar patterns of behaviour themselves (Bandura, 1986). Currently, research shows that organisations' cultures can be transferred to employees through modelling by their leaders (Schein, 1995) and that more specifically role models influence ethical conduct and pro-social behaviour (Brown et al., 2005). In the case of PEB, which concerns voluntary behaviour, managers cannot oblige employees to engage in these behaviours, managers can only encourage employees to engage in PEB. One possible way to achieve this, as mentioned by Paillé and Boiral (2013), is by showing their own commitment to PEB; showing environmental leadership and communicating green policies can send positive signals to employees and subsequently can help promote green behaviour. Leadership provided by immediate line managers is especially important; in general these managers are in close contact with their employees and may have a significant influence on employees' PEB (Andersson et al., 2005). Graves et al. (2013) unravelled this relation already on one aspect: when managers are engaged in high transformational leadership, employees associate external motivation with increases in PEB and when managers' transformational leadership is low, employees associate external motivation with declines in PEB. Based on this, it is expected that exemplary behaviour by leaders (the concept is labelled as leadership behaviour) has a significant effect on the intention of employees to act pro-environmentally.

An additional implication comes from the relationship between PEB and employees' beliefs about the importance of sustainability within their organisation. There are often several activities management can undertake when they wish their employees to go above and beyond their job responsibilities. One way is to demonstrate that the organisation is concerned about the environment, such as placing well-marked recycling receptacles in convenient areas or managers who notice and appreciate green behaviours. Blok et al. (2015) conclude that, besides the common factors of TPB, especially leadership support (actively showing the importance of sustainability by both the managers and organisation) to act pro-environmental friendly has an impact on PEB in the workplace.
Whereas Paillé and Boiral (2013) emphasize the importance of leadership behaviour (role modelling) and Blok et al. (2015) underpin the crucial role of leadership support (purposeful activities by both managers and organisation to show the importance of sustainability), other scholars emphasize the role of POS-E (Lamm et al., 2015 for example) to positively influence PEB in the workplace. According to Robertson and Barling (2013) research should study the effects of leadership in conjunction with other organisational relevant variables in promoting PEB in the workplace. Therefore, in this study leadership behaviour is studied in conjunction with POS-E and leadership support. POS-E and leadership support are studied both in an integrated (combined labelled as institutional support) and separate fashion in relation to PEB to unravel the relationship between both concepts. Institutional support is defined as the activities an organisation and its managers can bring forward to foster employees' PEB and appreciation thereof. Whereas leadership support is seen is a more active way to encourage PEB (activities a managers can do), POS-E has a more passive nature (it is determined by the employees' perception of policies for example). Fig. 1 summarizes all factors affecting PEB. The following research questions are central in this study:

1) To what extent does institutional support (consisting of POS-E and leadership support) influence employees' (intention to) PEB?

2) To what extent does (exemplary) leadership behaviour influence employees' (intention to) PEB?

As mentioned before, TPB is an often used theory but only occasionally used in the setting of the workplace. Therefore, TPB needs additional validation to ensure this model can be applied to explain PEB in the workplace and therefore a third research question is added:

3) To what extent is the TPB applicable in the private company setting to explain factors affecting PEB?

\section{Research methods}

\subsection{Procedure and participants}

Four housing associations participated in this study; the largest one is active in the east, centre, and west part of the Netherlands, while the other three are only active in the southern region in the Netherlands. All of the participating associations have a mission statement that says that they not only supply homes, but they also have a responsibility to improve the 'liveability' of neighbourhoods. The housing associations agreed to send a web-based survey to their employees using an electronic mailing list. In this way crosssectional data was collected to answer the research questions as formulated in the theoretical framework. The same data collection procedure was followed for each association. In total 540 employees started the survey. The survey website contained an introductory page providing information on the study and a consent statement. To increase participation rate and avoid confusion with undesirable messages and junk mail, representatives of all four housing associations sent an e-mail with a message explaining the purpose of the study to their employees. The same mail contained a URL link to the survey website. Once a participant completed the survey, the related file was automatically entered into a database and anonymity was preserved. 


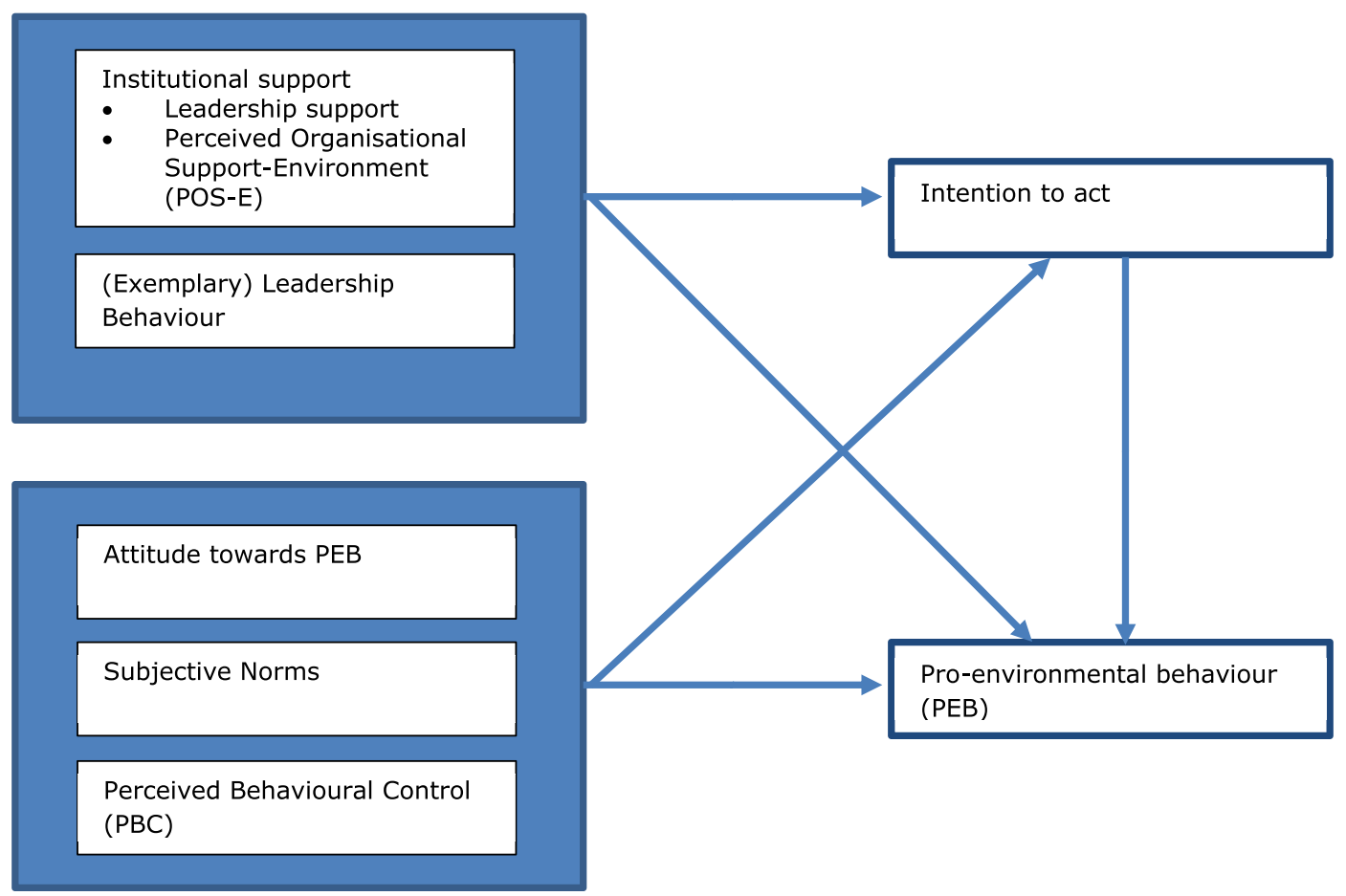

Fig. 1. Factors affecting pro-environmental behaviour (PEB) in the workplace, based on TPB.

\subsection{Questionnaire}

All variables in the questionnaire, except demographic data, are measured on a 5-point Likert-scale. Based on Blok et al. (2015) the variables PEB, attitude towards PEB, perceived behavioural control, subjective norms and intention to act are used and adjusted to the housing association context if necessary. Appendix A shows the full questionnaire.

The first part, after some general questions like age and gender, focused on questions on actual PEB in the workplace. The questions aimed to capture the actual behaviour that was performed by the employees in their offices and in relation to their work. Therefore, the questions measured how often they do certain activities related to heating, printing and copying, drinking hot beverages and sustainable shopping. An example of a question is: 'I use scrap paper rather than a new sheet of paper to make notes'. The answers were captured on a scale from 1 (= 'never') up to 5 (= 'always'). The lowest number indicated poor PEB and the highest the best possible. The number 0 indicated that there were no facilities or no possibilities available to perform pro-environmentally. To come to an overall score for PEB the average was taken of at least six of the items representing PEB activities mentioned in the survey. For a large part of the respondents it appeared that they could not answer all questions regarding PEB, because they were not able to influence the circumstances in their offices. For example, because of a central heating system in one of the housing associations, employees are not able to influence the heating in their offices. And based on the fact that this study is not per se interested in whether or not an individual employee always turns off the lights or heating; this study aims at grasping an overall average of PEB, it is assumed acceptable to work with an average of at least six items. In other words, when respondents answered more than three times 'not applicable' (0), these respondents were not included in the analysis. In this way, a composite score was generated for the respondents, which reflected their PEB, though the score for different employees may be generated out of the ratings of different PEB items. In total 479 respondents (of 540 respondents in total which equals $88 \%$ ) completed six or more PEB scores.

The intention to act was measured by one item mentioning a cognitive representation of respondents' readiness to show green behaviours in the coming month. The intention was measured on a scale from $1=$ Strongly disagree to $5=$ Strongly agree. A low score means the respondent has a low intention and a high score means there is a high intention to show PEB.

The three antecedents of the intention to act proenvironmentally are conceptualized in the following way. Firstly, subjective norms are operationalized in terms of social norms at work. The scale was constructed based on the study by Borgstede and Anders (2002) and Blok et al. (2015) and measures the expectation held by others to behave pro-environmentally in the workplace yourself. The strength of social norms was assessed with statements related to the norms measured on a scale from 1 (=absolutely not) up to 5 (=absolutely). Higher numbers indicate a higher expectation by others to show PEB. Attitudes were based on the study done by Blok et al. (2015) and operationalized in terms of attitudes with regard to PEB. These attitudes were measured by the degree to which behaving pro-environmentally was positively or negatively assessed by the individual employee. Twelve different statements related to PEB in the workplace were created to measure pro-environmental attitude and the scales ranged from $1=$ Strongly disagree to $5=$ Strongly agree. A low score indicates not much attitude in favour of PEB and a high score means a positive attitude towards PEB. Also based on Blok et al. (2015) PBC was operationalized by means of employees' perceptions of their ability to perform pro-environmentally. The respondents indicated to what extent they can perform PEB on a scale from $1=$ Strongly disagree to $5=$ Strongly agree. A high score shows high $\mathrm{PBC}$ and a low score indicates low PBC. 
The variable leadership behaviour is adopted from the study of Blok et al. (2015) and contains three statements: 'I show PEB when my direct supervisor behaves pro-environmentally in the workplace','It is important to me that my direct supervisor shows PEB at the workplace' and 'Seeing my direct supervisor acting proenvironmentally influences my own acting. The statements with regard to leadership behaviour could be answered on a range from $1=$ Strongly disagree to $5=$ Strongly agree.

Whereas Blok et al. (2015) used solely leadership support in their study, in this study this variable is accompanied by POS-E and together they get the label institutional support. This variable originally focuses on active forms of managerial support. For example, it measures whether management actively informs employees on environmental effects of the work of the employee (Blok et al., 2015). POS-E measures whether an employee feels supported by her or his organisation, i.e. by the attitude of the organisation regarding (the actions of) the employee (Eisenberger et al., 1986; Lamm et al., 2015). The variable leadership support used in this study is therefore augmented with three questions of POS-E (Eisenberger et al., 1986).

\subsection{Data analysis}

Data analysis started with a principal component analysis (PCA), with orthogonal rotation (varimax). This was done to test for unidimensionality for each separate variable with the criterion of eigen value $>1$. The factorability was examined by checking the anti-image correlation matrix (low values), and measures of sampling adequacy (MSAs) tested by Kaiser-Myer-Olkin (KMO $>0.5)$ and Bartlett's test of sphericity (significant at 5\%). All constructs have a KMO value equal to or higher than 0.5 , which is the cut-off point. In each component analysis the correlations of the items proved to be not too low, given that each Bartlett's test yielded significant values.

The reliability of the scales was tested by Cronbach's alpha's to confirm good internal correlation of each item in the scale. A Cronbach's alpha above 0.7 indicates a good internal reliability. To answer the research questions, an ordinary least squares (OLS) regression was used. All analyses are executed using IBM SPSS Statistics 22.

\section{Results}

In total 540 employees started the survey and of 479 employees data for all relevant constructs was available and their responses could be used for the analysis. There were no significant differences between the four housing associations and therefore the data of all housing associations were analysed together. In Table 1 , the descriptives of the constructs are presented. PEB has an average of 4.01 (on a 5 point Likert scale) with a standard deviation of 0.60 . ${ }^{1}$ Attitude towards PEB is high and positive 4.21 ( $\mathrm{sd}=0.58$ ) with a Cronbach's alpha of 0.79. Also the mean score on subjective norm is relatively high with 4.19 accompanied with a sd of 0.71 and Cronbach's alpha of 0.77 . PBC has an average score of 3.89 with a sd of 0.79 and Cronbach's alpha of 0.51. This Cronbach's alpha is not sufficient according to common rules. This indicates that the items do hardly correlate, however there were only two items measuring $\mathrm{PBC}$ and that might explain the low reliability of the scale. The intention to act is about average with 3.16 (sd 1.01) and only concerns one item and therefore no Cronbach's alpha. The scores on

\footnotetext{
1 As PEB is measured by factual statements and not perceptual questions, it has the form of a formative scale. Cronbach's alpha is therefore not relevant for this
} scale.
Table 1

Mean values, standard deviations, and scale reliability (Cronbach's alpha) for the applied measures of factors affecting PEB in the workplace.

\begin{tabular}{llll}
\hline Items $(\mathrm{N}=479)$ & Mean & Std dev & Cronbach's alpha \\
\hline Pro-environmental Behaviour (PEB) & 4.01 & 0.60 & \\
Attitude towards PEB & 4.21 & 0.58 & 0.79 \\
Social Norm & 4.19 & 0.71 & 0.77 \\
Perceived Behavioural Control & 3.89 & 0.79 & 0.51 \\
Intention to act & 3.16 & 1.01 & - \\
Institutional Support (IS) & 2.79 & 0.86 & 0.92 \\
POS-E & 2.74 & 0.94 & 0.84 \\
Leadership support & 2.84 & 0.88 & 0.88 \\
Leadership Behaviour (LB) & 3.48 & 0.76 & 0.74 \\
Age & 3.01 & 1.01 & - \\
Gender & 1.54 & 0.50 & - \\
\hline
\end{tabular}

the variables outside TPB where lower in comparison to these scores. The mean of institutional support is 2.79 with sd 0.86 and a Cronbach's alpha of 0.92 . When institutional support is split up in POS-E and leadership support, POS-E has a mean of 2.74 (sd of 0.94 and Cronbach's alpha of 0.84) and leadership support has a mean of 2.84 , sd of 0.88 and Cronbach's alpha of 0.88 . The mean score on leadership behaviour is also relatively low; the mean is 3.30 , sd is 0.76 and Cronbach's alpha is 0.74 . The majority of the respondents is male and has mainly an age around 30 years old. To conclude, most variables show good reliability. $\mathrm{PBC}$ is below the threshold of 0.70 . Appendix B shows that the correlations are well below the threshold of 0.80 indicating that discriminant validity is not a problem in this study.

To test the effects of the different factors on the intention to act and on PEB in the workplace, multiple regression analysis were done. The results of the first analysis are reported in Table 2 . In this table the regressions are presented to what extent factors influence intention to act. The overall model is significant with an F-statistic of 24.92.The $R^{2}$ is 0.22 . In this regression multicollinearity is not an issue, because the highest variance inflation factor (VIF)-indices is 1.6 and that is below the threshold of 10 (Field, 2009). The factor leadership behaviour has the most significant relation with intention to act with a coefficient of 0.263 and this is in line with earlier findings (i.e. Blok et al., 2015). Furthermore, institutional support and subjective norms have both a strong significant effect with coefficients of respectively 0.109 and 0.193 .

A second regression was done to see to what extent the identified factors affect PEB (see Table 3). The overall model is significant with an F-statistic of 19.30 and $R^{2}$ is 0.25 . The highest VIFindices is 1.8 and again multicollinearity is not an issue. Three factors have a significant contribution at a $1 \%$ level. Firstly, attitude towards PEB; a strong attitude towards pro-environmental behaviour relates with more PEB. Secondly, institutional support is highly significant. Higher institutional support has a positive

Table 2

Direct effects of factors on intention to act pro-environmentally.

\begin{tabular}{lllll}
\hline & $\mathrm{B}$ & Std. Err. & $p$-value & \\
\hline Institutional support & 0.159 & 0.065 & 0.016 & $* *$ \\
Leadership behaviour & 0.365 & 0.073 & 0.000 & $* * *$ \\
Attitude towards PEB & 0.071 & 0.091 & 0.440 & \\
Subjective Norms & 0.318 & 0.076 & 0.000 & $* *$ \\
Perceived Behavioural Control & 0.070 & 0.061 & 0.252 & \\
Age & 0.066 & 0.047 & 0.159 & \\
Gender & 0.061 & 0.096 & 0.523 & $*$ \\
Constant & -0.773. & 0.442 & 0.098 & $*$ \\
Model $F$-Stat & 24.92 & & & $*$ \\
$R^{2}=0.22$ & & & & \\
\hline $\mathrm{N}=479,{ }^{*} \mathrm{p}<0.1 ;{ }^{* *} \mathrm{p}<0.05 ;{ }^{* * *} \mathrm{p}<0.001$. & & & \\
\end{tabular}


Table 3

Direct effects of factors affecting pro-environmental behaviour in the workplace.

\begin{tabular}{lllll}
\hline & Coefficient & Std. Err. & $p$-Value & \\
\hline Intention to act & 0.029 & 0.025 & 0.238 & \\
Institutional Support & 0.103 & 0.035 & 0.003 & $* * *$ \\
Leadership Behaviour & 0.072 & 0.040 & 0.072 & $*$ \\
Attitude towards PEB & 0.319 & 0.049 & 0.000 & $* * *$ \\
Subjective Norms & 0.110 & 0.041 & 0.008 & $* * *$ \\
Perceived Behavioural Control & 0.011 & 0.032 & 0.725 & \\
Age & 0.037 & 0.025 & 0.136 & \\
Gender & -0.0 .65 & 0.051 & 0.205 & $* * *$ \\
Constant & 1.525 & 0.236 & 0.000 & $* * *$ \\
Model $F-S t a t$ & 19.30 & & 0.000 & \\
$R^{2}=0.25$ & & & &
\end{tabular}

$\mathrm{N}=479,{ }^{*} \mathrm{p}<0.10 ;{ }^{* *} \mathrm{p}<0.05 ;{ }^{* * *} \mathrm{p}<0.01$.

Table 4

Direct effects of POS-E and leadership support on intention to act pro-environmental friendly.

\begin{tabular}{lllll}
\hline & Coefficient & Std. Err. & $p$-Value & \\
\hline Leadership support & -0.012 & 0.087 & 0.887 & \\
POS-E & 0.165 & 0.082 & 0.045 & $* *$ \\
Leadership Behaviour & 0.365 & 0.073 & 0.000 & $* * *$ \\
Attitude towards PEB & 0.077 & 0.091 & 0.402 & \\
Subjective Norms & 0.319 & 0.076 & 0.000 & $* * *$ \\
Perceived Behavioural Control & 0.065 & 0.061 & 0.289 & \\
Age & 0.070 & 0.047 & 0.136 & \\
Gender & 0.056 & 0.096 & 0.558 & \\
Constant & -0.720 & 0.442 & 0.104 & $* * *$ \\
Model F-Stat & 16.409 & & 0.000 & \\
$R^{2}=0.22$ & & & & \\
\hline $\mathrm{N}=479,{ }^{*} \mathrm{p}<0.10 ;{ }^{* *} \mathrm{p}<0.05 ;{ }^{* * *} \mathrm{p}<0.01$. & & & \\
\end{tabular}

$\mathrm{N}=479,{ }^{*} \mathrm{p}<0.10 ;{ }^{* *} \mathrm{p}<0.05 ;{ }^{* * *} \mathrm{p}<0.01$.

Table 5

Direct effects of POS-E and leadership support on actual PEB in the workplace.

\begin{tabular}{lllll}
\hline & Coefficient & Std. Err. & $p$-Value & \\
\hline Intention to act & 0.028 & 0.025 & 0.257 & \\
Leadership support & 0.015 & 0.046 & 0.747 & \\
POS-E & 0.086 & 0.044 & 0.050 & $* *$ \\
Leadership Behaviour & 0.073 & 0.040 & 0.070 & $*$ \\
Attitude towards PEB & 0.322 & 0.049 & 0.000 & $* * *$ \\
Subjective Norms & 0.110 & 0.041 & 0.008 & $* * *$ \\
Perceived Behavioural Control & 0.009 & 0.032 & 0.771 & \\
Age & 0.039 & 0.025 & 0.121 & \\
Gender & -0.067 & 0.051 & 0.193 & $* * *$ \\
Constant & 1.529 & 0.236 & 0.000 & $* * *$ \\
Model F-Stat & 17.223 & & & \\
$R^{2}=0.25$ & & & & \\
\hline $\mathrm{N}=479,{ }^{*} \mathrm{p}<0.10 ;{ }^{* *} \mathrm{p}<0.05 ;{ }^{* * *} \mathrm{p}<0.01$. & & & \\
\end{tabular}

association with actual PEB. Thirdly, subjective norms positively associates with actual PEB; the higher the score on subjective norms, the higher the score on actual PEB. With regard to subjective norms, this is in line with former studies that showed the same relation. Finally, leadership behaviour shows a significant relation with actual behaviour at a $10 \%$ level. In former studies of Blok et al. (2015) and Andersson et al. (2005) both results could be recognized. All other variables are not significant; there is even no significant relation between intention to act and PEB.

In a complementary regression analysis POS-E and leadership support (in the former analysis both part of institutional support) are treated as two different constructs. Table 4 (dependent variable intention to act) and Table 5 (dependent variable PEB) show the regression outcomes. It appeared that POS-E (perceived organisational support - environment) has a significant relationship at a 5\% level with both intention to act and actual PEB. Leadership support does not have a significant relationship with one of them. So the relationship of institutional support is mainly on the account of POS-E. Leadership support does not seem to make a difference.

\section{Discussion}

First, based on the results described in this article, there was no significant relation found between intention to act and actual PEB. How can this be explained? Outcomes with regard to TPB are diverse (Sniehotta et al., 2014). Some studies do find a significant relationship between intention to act and actual PEB (in households, see for example Heath and Gifford, 2002) others do not find this relationship. Blok et al. (2015) as one of the first to apply TPB in the field of workplaces and PEB, did find a significant relationship between intention to act and PEB. Their study took place in the context of universities; example of an organisation in the public sector. In the study at stake, this relationship could not be detected and this could be seen as remarkable. However, it can probably be explained by the fact that this study took place in an organisation in the private sector. This finding reinforces Hahn and AragónCorrea's (2015) suggestion that employees' personal beliefs about and intentions for sustainability (initiatives) may be not be aligned with what they themselves do at work. In the private sector, the business case arguments for engaging in CSR are dominant and remain directive for employees' behaviour and are not necessarily in line with employees' attitudes. Even though the housing associations also have a social goal, probably the business logic is dominant and that makes that the contextual factors are not neutral, which implies a gap between attitude and behaviour (Nye and Hargreaves, 2010). This confirms the statement, as done by Sniehotta et al. (2014) that the TPB should be validated in each and every context. Although, the association between intention to act and actual PEB was not found, the outcomes of this study are interesting enough to be discussed. To show all the implications of this study, the results for both intention to act and actual PEB will be discussed.

As stated by Blok et al. (2015) and adopted in this study the common factors of TPB do not suffice in explaining PEB in the workplace. According to them the factors subjective norms and leadership support have an impact on actual PEB. In contrast with the findings by Blok et al. (2015) leadership support does not have a direct influence on actual PEB. In this study, leadership support was initially measured as part of institutional support. However, the counterpart factor POS-E, explained most of the variance and had a significant association with actual PEB (also demonstrated by Lamm et al., 2015; Temminck et al., 2015). Leadership support did not have a significant effect, in contrast to the results of Blok et al. (2015). According to the housing associations' employees neither the efforts of heads of department (or bosses) to actively support them in showing PEB nor the efforts to inform them about sustainability projects or environmental policies are helpful. Considering the low score on institutional support, the explanation might be that managers at housing associations do not put much effort in supporting and informing employees which consequently does not affect employees' PEB. Or managers do show behaviour alike, but employees do not perceive it as such.

In university setting this is apparently different, because leadership support showed a significant relation with PEB in the study done by Blok et al. (2015). A more active approach of (line) managers to encourage PEB is appreciated more in public sectors than in 
private sectors. Maybe because of the multiple or even conflicting messages private sector managers have to convey; on the one hand they want to encourage PEB (it is the norm) and on the other hand they have to make sure they reach their (financial) targets. On the contrary, POS-E (the other element of institutional support) does have a significant effect on PEB (and intention to act). So, the organisation (in this case housing associations) as such can make a difference in a more passive way, because there is a significant relationship between actual PEB and the activities the organisation shows (i.e. takes care whether an employee is satisfied about the environmental policy, or is willing to extend itself if the employee is willing to perform its job as environmentally friendly as possible). This is in line with the conclusions of Norton et al. (2014) in which they confirmed a relationship between task-related EGB and the presence of an organisational environmental/sustainability policy. So, on the level of the support of managers and bosses, there is no effect. On the level of the organisation as a whole there is both an effect on actual PEB as on intention to act.

Given this result, it is considered interesting to emphasize this for those who start a social enterprise or consider to work with social business models. Employees in the private sector, where the business logic (i.e. making profit) is the most prominent value (see also Osagie et al., 2016), could be supported less towards PEB in comparison to employees who work in a public sector. However, on the level of the organisation, sustainability policy could make a difference also in the private sector. This conclusion might suggest that people who like to work for a social enterprise or are attracted by a sustainable business model (with not just money as the only value and therefore considered as public sector) could be influenced to show PEB by both information and support by their manager and a sustainability policy.

With regard to the results, the final outcome to be discussed is leadership behaviour (exemplary behaviour of the manager). In this study leadership behaviour does have a significant relation with intention to act pro-environmentally and actual PEB. This is in contrast with the results of Blok et al. (2015) in which exemplary leadership behaviour only had an effect on intention to act. In housing associations the actual behaviour of employees is associated with the behaviour of their direct managers by means of their (exemplary) behaviour. So, where the leadership support did not have any significant effect on neither PEB nor intention to act, the (more passive) behaviour of managers and bosses themselves does make a difference. Employees (are willing to) show PEB and as long as their managers also show similar behaviour. This result confirms other research in which the importance of role models are stressed (e.g. Ramus and Steger, 2000). Managers and bosses of housing associations should be aware of this. The same holds for social entrepreneurs and starters of sustainable business models. They should realize that they play a significant role as role model when it concerns their employees' PEB. Furthermore, this finding implies that not just the TPB should be validated in each context, also the contextual factors influencing intention to act and actual PEB should be studied in each context.

The overall variance explained by the factors in actual PEB is 0.25 which could be perceived as relatively low. However, the study done by Blok et al. (2015) showed an $R^{2}$ of 0.19 for actual PEB. In comparison to Blok et al. (2015) the design of this study is less complicated and extensive by not including all kinds of personal values and norms. Although Fishbein and Ajzen (2010) argue to include a measure of moral norms in cases in which behaviours are measured which have a clear moral dimension (as in the case of PEB), this study shows that does not necessarily increase the amount of variance explained. In follow-up studies it would be interesting to include the line managers' role and their competencies to realize CSR and to encourage PEB. The importance of moral values (which come into play in concepts like PEB and CSR because of the normative character of these concepts) especially come into play in interaction (e.g. negotiations) with others and therefore normative and interpersonal competencies could be important for managers who want to encourage CSR and PEB (Osagie et al., 2014; Wesselink et al., 2015).

This study knows several limitations. Firstly, the measurements in this study were cross-sectional of nature and collected within four housing associations. Although there were no differences between the housing associations as such, it is important that this kind of studies are repeated in different contexts to assess the value of these outcomes and they should get a longitudinal character to become decisive on the causal relationships between factors and outcomes. This would increase the generalizability of the findings. Secondly, only the perspectives of the subordinates were taken into account in this research. In followup studies it would be recommended to also take into account the viewpoint of the supervisors. Thirdly, all the data gathered was on the basis van self-assessment. Future research should try to integrate a more objective form of measuring actual PEB data. In this study the choice was made that it was not necessary to act environmental friendly on all aspects of printing, heating, etc. Future research could take one aspect of PEB into account and complement a subjective measure with an objective measure (double sided printing e.g.). Fourthly, knowing the important role of the direct supervisor, it would be necessary to do interventions with the help of supervisors to see what aspects of their exemplary behaviour are enhancing PEB.

\section{Conclusions}

The aim of this study was to unravel factors that affect PEB of individual employees, who are seen as important contributors to realize successful implementation of CSR and sustainability in existing businesses. In addition to the known factors of the TPB (attitude towards PEB, subjective norms, perceived behavioural control, and intention to act), factors as leadership support, perceived organisational support for the environment (POS-E) (taken together as institutional support), and leadership behaviour were taken into account. Although the relationship between intention to act and PEB was not significant in this study, the results in relation to intention to act and PEB separately are interesting. Based on the findings it can concluded that there is an association between leadership behaviour (as exemplary behaviour) and POS-E or in other words the perceived organisational support to act pro-environmentally friendly, and both intention to act and actual PEB. It is remarkable that leadership support does not have a positive relation with intention to act and actual PEB.

The findings of this research stress the importance of the direct supervisors' behaviour and the role of sustainability policy. They should not support their employees in acting more green, they should show the right behaviour themselves and employees will learn from that and change their behaviour accordingly. Managers should be aware of their influence. Furthermore, organisations should acknowledge, develop and enhance employees' PEB by sharing their policies, facilitating employees as much as possible and offer them ample possibilities to show PEB.

Based on the interpretation of differences between studies in private and public sector, it could be argued (with caution, because only based on two studies) that employees in these two 
different sectors should be approached differently. Whereas the relation between attitude and PEB shows a significant relation in the public sector, this relation could not be detected in the private sector. Apparently, there exists a gap between intentions and actual behaviour in the private sector. Furthermore, managers in the private sector could stop with informing and supporting their employees to show PEB, because there is no clear relationship, contrary to the public sector. In both sectors indications show that it is beneficial for managers to be aware of their own exemplary behaviour and as organisation to have a sustainability policy.

\section{Appendix A. Questionnaire}

\begin{tabular}{|c|c|c|}
\hline Concept & Survey question & Response categories \\
\hline Pro-environmental behaviour & $\begin{array}{l}\text { Please indicate to what extent you agree with the following statements: } \\
\text { - I recycle as much as possible } \\
\text { - I use scrap paper rather than new paper for notes } \\
\text { - If I would live close to work, I would go to work by bicycle (or walking) rather than by car } \\
\text { - I turn off the lights when I am the last to leave the office } \\
\text { - I turn off the lights in empty rooms when I pass them } \\
\text { - I turn off all my electronic devices at the end of the day } \\
\text { - If it would be offered in our canteen, I would choose organic food and beverages } \\
\text { - I use a new paper/plastic cup for each cup of coffee/tea (reverse coded) } \\
\text { - I take care to turn off or down the heating outside office hours }\end{array}$ & $\begin{array}{l}0=\mathrm{N} / \mathrm{A} \\
1=\text { strongly disagree } \\
2=\text { disagree } \\
3=\text { neutral } \\
4=\text { agree } \\
5=\text { strongly agree }\end{array}$ \\
\hline Intention to act & $\begin{array}{l}\text { Please indicate to what extent you agree with the following statement: } \\
\text { - In the coming month I have the intention to behave more pro-environment friendly. }\end{array}$ & $\begin{array}{l}1=\text { strongly disagree } \\
2=\text { disagree } \\
3=\text { neutral } \\
4=\text { agree } \\
5=\text { strongly agree }\end{array}$ \\
\hline $\begin{array}{l}\text { Institutional support (including } \\
\text { Leadership support (LS) and } \\
\text { POS-E) }\end{array}$ & $\begin{array}{l}\text { Please indicate to what extent you agree with the following statements: } \\
\text { - My boss/head of the department supports me in showing pro-environmental behaviour at work. (LS) } \\
\text { - My employer informs me about the environmental impact of my behaviour at work. (LS) } \\
\text { - My employer informs me about projects on sustainability at my housing association (LS) } \\
\text { - My employer informs me about environmental policy of my department (LS) } \\
\text { - I learn environmental friendly behaviour at work (LS) } \\
\text { - There is a supervisory support for the environmental effort of the employees (LS) } \\
\text { - The organisation cares whether I am satisfied with the environmental policy and how employees } \\
\text { behave accordingly (POS-E) } \\
\text { - The organisation takes pride in the way I perform environmentally friendly at work (POS-E) } \\
\text { - The organisation is willing to extend itself if I would want to perform my job as environmentally as } \\
\text { possible (POS-E) }\end{array}$ & $\begin{array}{l}1=\text { strongly disagree } \\
2=\text { disagree } \\
3=\text { neutral } \\
4=\text { agree } \\
5=\text { strongly agree }\end{array}$ \\
\hline Leadership behaviour & $\begin{array}{l}\text { Please indicate to what extent you agree with the following statements: } \\
\text { - I show the pro-environmental behaviour, when my boss/head of the department behaves pro- } \\
\text { environmentally in the workplace. } \\
\text { - It is important to me that my boss/head of the department shows pro-environmental behaviour at } \\
\text { work. } \\
\text { - Seeing my boss/head of the department acting pro-environmentally influences my own acting }\end{array}$ & $\begin{array}{l}1=\text { strongly disagree } \\
2=\text { disagree } \\
3=\text { neutral } \\
4=\text { agree } \\
5=\text { strongly agree }\end{array}$ \\
\hline Attitude towards PEB & $\begin{array}{l}\text { Please indicate to what extent you agree with the following statements: } \\
\text { - I'm in favour of behaving pro-environmentally in the workplace. } \\
\text { - I think it's a good idea when the housing association as an employer supports pro-environmental } \\
\text { behaviour in the workplace } \\
\text { - An pro-environmental attitude in the workplace is important to me } \\
\text { - I think too much attention is paid to the pro-environmental behaviour in the workplace. (reverse } \\
\text { coded) } \\
\text { - I think it is good when colleagues show pro-environmental behaviour }\end{array}$ & $\begin{array}{l}1=\text { strongly disagree } \\
2=\text { disagree } \\
3=\text { neutral } \\
4=\text { agree } \\
5=\text { strongly agree }\end{array}$ \\
\hline Subjective norms & $\begin{array}{l}\text { What in your opinion should your colleagues do at work? } \\
\text {-Print double-sided? } \\
\text { •Copy double-sided? } \\
\text {-Recycle paper? } \\
\text {-Turn off the computer/notebook when not in use? } \\
\text {-Arrange a telephone or video-conference instead of travelling to a business meeting? }\end{array}$ & $\begin{array}{l}1=\text { strongly disagree } \\
2=\text { disagree } \\
3=\text { neutral } \\
4=\text { agree } \\
5=\text { strongly agree }\end{array}$ \\
\hline Perceived behavioural control & $\begin{array}{l}\text { Please indicate to what extent you agree with the following statements: } \\
\text {-If I wanted to, I could easily behave pro-environmentally in the workplace. } \\
\text {-Whether I perform pro-environmentally is entirely up to me. }\end{array}$ & $\begin{array}{l}1=\text { strongly disagree } \\
2=\text { disagree } \\
3=\text { neutral } \\
4=\text { agree } \\
5=\text { strongly agree }\end{array}$ \\
\hline Age & What is your age & \\
\hline Gender & What is your gender & $\begin{array}{l}\text { Male } \\
\text { Female }\end{array}$ \\
\hline Employer & Who is your employer & $\begin{array}{l}\text { Housing association A } \\
\text { Housing association B } \\
\text { Housing association C } \\
\text { Housing association D }\end{array}$ \\
\hline
\end{tabular}


Appendix B. Correlation matrix

\begin{tabular}{|c|c|c|c|c|c|c|c|}
\hline & PEB & $\begin{array}{l}\text { Intention to } \\
\text { Act }\end{array}$ & $\begin{array}{l}\text { Institutional } \\
\text { Support }\end{array}$ & $\begin{array}{l}\text { Leadership } \\
\text { Behaviour }\end{array}$ & $\begin{array}{l}\text { Attitude towards } \\
\text { Behaviour }\end{array}$ & $\begin{array}{l}\text { Subjective } \\
\text { Norms }\end{array}$ & $\begin{array}{l}\text { Perceived Behavioural } \\
\text { Control }\end{array}$ \\
\hline PEB & 1.000 & & & & & & \\
\hline Intention to Act & $0.243^{* * *}$ & 1.000 & & & & & \\
\hline Institutional Support & $0.206^{* * *}$ & $0.308^{* * *}$ & 1.000 & & & & \\
\hline Leadership Behaviour & $0.276^{* * *}$ & $0.385^{* * *}$ & $0.546^{* * *}$ & 1.000 & & & \\
\hline Attitude towards Behaviour & $0.393^{* * *}$ & $0.170^{* * *}$ & $-0.102^{* *}$ & $0.147^{* * *}$ & 1.000 & & \\
\hline Subjective Norms & $0.333^{* * *}$ & $0.301^{* * *}$ & $0.101^{* *}$ & $0.185^{* * *}$ & $0.481^{* * *}$ & 1.000 & \\
\hline Perceived Behavioural Control & $0.203^{* * *}$ & $0.214^{* * *}$ & $0.169^{* * *}$ & $0.239^{* * *}$ & $0.217^{* * *}$ & $0.305^{* * *}$ & 1.000 \\
\hline Gender & $-0.083^{*}$ & 0.009 & $0.117^{* * *}$ & 0.021 & $-0.114^{* *}$ & $0.207^{* * *}$ & 0.024 \\
\hline Age & $0.098^{*}$ & $0.079^{*}$ & $0.165^{* * *}$ & 0.007 & 0.013 & -0.004 & $0.103^{*}$ \\
\hline
\end{tabular}

${ }^{*} \mathrm{p}<0.1 ;{ }^{* *} \mathrm{p}<0.05 ;{ }^{* * *} \mathrm{p}<0.01$

\section{References}

Aguinis, H., Glavas, A., 2012. What we know and don't know about corporate social responsibility: a review and research agenda. J. Manag. 38, 932-968.

Ajzen, I., 1991. The theory of planned behavior. Organ. Behav. Hum. Decis. Process. $50,179-211$

Andersson, L., Shivarajan, S., Blau, G., 2005. Enacting ecological sustainability in the MNC: a test of an adapted value-belief-norm framework. J. Bus. Ethics 59, 295-305.

Andersson, L.M., Bateman, T.S., 2000. Individual environmental initiative: championing natural environmental issues in US business organisations. Acad. Manag. J. 43, 548-570.

Bandura, A., 1986. Social Foundations of Thought and Action: a Social Cognitive Theory. Prentice-Hall, Englewood Cliffs, NJ.

Bissing-Olson, M.J., Iyer, A., Fielding, K.S., Zacher, H., 2013. Relationship between daily affect and pro- environmental behavior at work: the moderating role of pro-environmental attitude. J. Organ. Behav. 34, 156-175.

Blok, V., Wesselink, R., Studynka, O., Kemp, R., 2015. Encouraging sustainability in the workplace: a survey on the pro-environmental behavior of university employees. J. Clean. Prod. 106, 55-67.

Boiral, O., 2009. Greening the corporation through organisational citizenship behaviors. J. Bus. Ethics 87, 221-236.

Borgstede, C.V., Anders, B., 2002. Pro-environmental Behavior: Situational Barriers and Concern for the Good at Stake. Göteborg Psychological Reports, 32.

Brown, M.E. Trevino, L.K., Harrison, D.A.,2005, Ethical leadership: a social learning perspective for construct development and testing. Organ. Behav. Hum. Decis Process. 97, 117-134.

Daily, B.F., Bishop, J.W., Govindarajulu, N., 2008. A conceptual model for organisational citizenship behaviour directed toward the environment. Bus. Soc. 48 243-256.

Eisenberger, R., Huntington, R., Hutchison, S., Sowa, D., 1986. Perceived organisational support. J. Appl. Psychol. 71, 500-507.

Field, A. 2009. Discovering Statistics Using SPSS, Sage publications.

Fishbein, M., Ajzen, I., 2010. Predicting Changing Behavior: the Reasoned Action Approach. Psychology Press (Taylor \& Francis), New York.

Galpin, T., Whittington, L., 2012. Sustainability leadership: from strategy to results. J. Bus. Strategy 33, 40-48.

Graves, L.M., Sarkis, J., Zhu, Q.H., 2013. How transformational leadership and employee motivation combine to predict employee proenvironmental behaviors in China. J. Environ. Psychol. 35, 81-91.

Hahn, T., Aragón-Correa, J.A., 2015. Towards cognitive plurality on corporate sustainability in organisation: the role of organisational factors. Organ. Environ. 28 , 255-263.

Heath, M., Gifford, R., 2002. Extending the theory of planned behavior: predicting the use of public transportation. J. Appl. Soc. Psychol. 32, 2154-2189.

Kollmuss, A., Agyeman, J., 2002. Mind the Gap: why do people act environmentally and what are the barriers to pro-environmental behavior? Environ. Educ. Res. 8, $239-260$.

Lamm, E., Tosti-Kharas, J., King, C., 2015. Empowering employee sustainability: perceived organisational support toward the environment. J. Bus. Ethics 128 207-220.

Lamm, E., Tosti-Kharas, J., Williams, E.G., 2013. Read this article, but Don't print it: organisational citizenship behavior toward the environment. Group \& Organ.
Manag. 38, 163-197.

Marrewijk, M. van, 2003. Concepts and definitions of CSR and corporate sustainability: between agency and communion. J. Bus. Ethics. 44, 95-105.

McEachan, R.R.C., Conner, M., Taylor, N.J., Lawton, R.J., 2011. . Prospective prediction of health-related behaviors with the Theory of Planned Behavior: a metaanalysis. Health Psychol. Rev. 5, 97-144.

Nye, M., Hargreaves, T., 2010. Exploring the social dynamics of proenvironmental behavior change. J. Industrial Ecol. 14, 137-149.

Norton, T.A., Zacher, H., Ashkanasy, N.M., 2014. Organisational sustainability policies and employee green behavior: the mediating role of work climate perceptions. J. Environ. Psychol. 38, 49-54.

Ones, D.S., Dilchert, S., 2012. Employee green behaviors. In: Jackson, S.E., Ones, D.S. Dilchert, S. (Eds.), Managing Human Resources for Environmental Sustainability. Jossey-Bass, San Francisco, pp. 85-116.

Osagie, E.R., Wesselink, R., Blok, V., Mulder, M., 2014. Individual competencies for corporate social responsibility: a literature and practice perspective. J. Bus. Ethics $1-20$.

Osagie, E.R., Wesselink, R., Blok, V., Mulder, M., 2016. Contextualizing individual competencies for managing the corporate social responsibility adaptation process the apparent influence of the business case logic. Bus. Soc. http:// dx.doi.org/10.1177/0007650316676270.

Oskamp, S., Harrington, M., Edwards, T., Sherwood, D., Okuda, S., Swanson, D., 1991. Factors influencing household recycling behaviours. Environ. Behav. 23, 494-519.

Paillé, P., Boiral, O., 2013. Pro-environmental behavior at work: construct validity and determinants. J. Environ. Psychol. 36, 118-128.

Poortinga, W., Steg, L., Vlek, C., 2004. Values, environmental concern, and environmental behaviour: a study into household energy use. Environ. Behav. 36 70-93.

Ramus, C.A., Killner, A.B.C., 2007. Corporate greening through prosocial extrarole behaviors - a conceptual framework for employee motivation. Bus. Strategy Environ. 16, 554-570.

Ramus, C.A., Steger, U., 2000. The roles of supervisory support behaviors and environmental policy in employee "ecoinitiatives" at leading-edge european companies. Acad. Manag. J. 43, 605-626.

Robertson, J.L., Barling, J., 2013. Greening organisations through leaders' influence on employees' pro- environmental behaviours. J. Organ. Behav. 34, 176-194.

Stern, P.C., 2000. Toward a coherent theory of environmentally significant behavior, J. Soc. Issues 56, 407-424.

Schein, E.H., 1995. The role of the founder in creating organisational culture. Fam. Bus. Rev. 8, 221-238.

Schultz, P.W., Oskamp, S., Mainieri, T., 1995. Who recycles and when? A review of personal and situational factors. J. Environ. Psychol. 15, 105-121.

Sniehotta, F.F., Presseau, J., Araujo-Soares, V., 2014. Time to retire the theory of planned behavior. Health Psychol. Rev. 8, 1-7.

Temminck, E., Mearns, K., Fruhen, L., 2015. Motivating employees towards sustainable behavior. Bus. Strategy Environ. 24, 402-412.

Ungar, S., 1994. Apples and oranges: probing the attitude-behavior relationship for the environment. Can. Rev. Sociol. Anthroploy 31, 288-304.

Wesselink, R., Blok, V., Van Leur, S., Lans, T., Dentoni, D., 2015. Individual competencies for managers engagaed in corporate sustainable management practices. J. Clean. Prod. 106, 497-506. 